\title{
Relationship between pelvic and linear body measurements in Dorper ewes
}

\author{
I.M. van Rooyen ${ }^{1}$, P.J. Fourie ${ }^{1 \#}$ \& L.M.J. Schwalbach ${ }^{2}$ \\ ${ }^{1}$ Department of Agriculture, Central University of Technology, Free State, Private Bag X20539, Bloemfontein 9300, \\ South Africa; ${ }^{2}$ Department of Animal, Wildlife and Grassland Sciences, University of the Free State, P.O. BOX 339, \\ Bloemfontein 9300, South Africa
}

Copyright resides with the authors in terms of the Creative Commons Attribution 2.5 South African Licence.
See: http://creativecommons.org/licenses/by/2.5/za/
Condition of use: The user may copy, distribute, transmit and adapt the work, but must recognise the authors and the South African Journal
of Animal Science

\begin{abstract}
Low lifetime rearing success and high perinatal mortality of lambs have been associated with small pelvic areas in ewes. It would therefore make sense to include pelvic area as a criterium for selecting breeding ewes; however, measuring it in vivo poses some challenges. The aim of this study was to determine pelvic height, width and area and to estimate correlations between these measurements and other external linear body parameters, i.e. body height, shoulder height, chest depth, front quarter width, hindquarter width, rump length and rump slope in Dorper ewes. A total of 332 young Dorper ewes ( \pm 12 months old; $48.0 \pm 5.9$ $\mathrm{kg}$ ) were used. The overall mean pelvic area of yearling Dorper ewes was $35.4 \pm 4.9 \mathrm{~cm}^{2}$. Registered ewes recorded significantly larger pelvic areas $\left(37.4 \pm 4.3 \mathrm{~cm}^{2}\right)$ than commercial ewes $\left(33.9 \pm 3.8 \mathrm{~cm}^{2}\right)$. Results also indicate no correlations between pelvic measurements and other body measurements considered in this study, indicating the need to measure the pelvic area of ewes directly. The pelvic meter and techniques used in this study proved to be relatively easy to use in measuring the pelvises of sheep.
\end{abstract}

Keywords: Dorper ewes, dystocia, linear body measurements, pelvic dimensions, pelvic meter, pelvis

\#Corresponding author: pfourie@cut.ac.za

\section{Introduction}

Small pelvises in ewes are associated with high incidences of dystocia, high perinatal ewe and lamb mortality rates and poor lifetime rearing performance of ewes (Haughey et al., 1982; Kilgour et al., 1993; Hartwig, 2002). In addition, dystocia is associated with prolonged postpartum periods, uterine infections and increased non -reproductive days as well as reductions in overall conception rate and milk production (Sieber et al., 1989; Walker et al., 1992). It would thus make sense to include pelvic area as a criterium in selecting breeding ewes. However, measuring this in vivo poses some practical challenges due to the smaller size of ewes in comparison to cattle.

Body size (length, height, etc.) and conformation can be described using simple measurements and visual assessment. How these measurements relate to the functional efficiency of the animal is of paramount importance to livestock production. The aim of this study is to determine pelvic height, width and area and to estimate correlations between these measurements and other external linear body parameters, i.e. body height, shoulder height, chest depth, front quarter width, hindquarter width, rump length and rump slope in Dorper ewes. Similarly, some breed conformation traits were correlated with pelvic measurements.

\section{Materials and Methods}

A pelvic meter was specially developed for sheep, in collaboration with the Science Park of the Central University of Technology, Free State (CUT), Bloemfontein, South Africa. The pelvic meter was pretested at the Bloemfontein abattoir on 90 randomly selected sheep just prior and after slaughtering. The correlations between the pre- and post-slaughter pelvic measurements were very high (height: $\mathrm{R}^{2}=0.80, P$ $<0.05$; width: $\mathrm{R}^{2}=0.87, P<0.05$; area: $\mathrm{R}^{2}=0.85, P<0.05$ ). 
A total of 332 Dorper ewes (ca 12 months old with a live weight of $48.0 \pm 5.75 \mathrm{~kg}$ ), from three different breeders, were used in the study. Ewes were kept extensively on veld in the Central Northern Cape region and received only a salt lick supplementation.The pelvises of all the ewes were measured once, using a method adapted from Haughey et al. (1982), Walker et al. (1992), Kilgour et al. (1993) and Patterson et al. (1997). At measuring, ewes, while standing in a chute, were restrained using a light squeeze; at first, faeces were removed from the rectum by hand after which the forceps of the instrument were carefully placed into the rectum (Deutscher, 1975). Once the pelvic meter was inserted into the animal's rectum, the forceps were opened while applying light pressure on the handle of the instrument. The pelvic meter, while being inserted, was then twisted from left to right for the operator to feel the ossified joint on the symphysis pubica, in order to find the point to measure the pelvic height $(\mathrm{PH})$; this is the largest distance between the pubic tubercle on the floor of the pelvis and the sacrum on the pelvic roof. The pelvic meter was then turned about $90^{\circ}$ sideways at the same point (pelvic inlet at its widest point), to measure the pelvic width (PW) which is the largest distance between the right and left corpura ilii. After removal from the rectum, the instrument was thoroughly cleaned with a mild disinfectant solution before using it in another ewe. The pelvic area (PA) of each animal was calculated as $\pi(\mathrm{PH} / 2) *(\mathrm{PW} / 2)$ (Morrison et al., 1986).

The following body parameters were also measured according to methods described by Fourie et al. (2002): live weight (LW); shoulder height (SH); chest depth (CD); shoulder width (SW); hindquarter width (HW) and rump length (RL). These parameters were correlated with the PH, PW and PA. In addition, the ewes were assessed visually for conformation (CM) and selection type (S), as described by the Dorper breed Standards of Excellence, on a scale of 1 - 5. Conformation scores range from 1 (being very poor) to 5 (being very good); selection type $1,2,3,4$ and 5 indicates cull, $2^{\text {nd }}$ selection, commercial, type 4 stud and type 5 stud, respectively. Rump slope (RS) scores ranged from 1 (being very flat) to 5 (being very droopy). Analyses of variance were conducted to compare means of different parameters using GLM procedures of SAS (SAS, 1989). Product moment correlations between the variables were also calculated. A stepwise regression was carried out to determine the individual effect of body measurements on pelvic area. An $\mathrm{F}$ to enter level of 0.10 was used to determine the significance of the partial contribution of each effect. Pelvic area was included as a covariate.

\section{Results and Discussions}

The means and standard deviations (SD) for the different body parameters considered in this study are presented in Table 1. The mean values for PH and PW in 12 months old Dorper ewes varied little, as

Table 1 Means \pm standard deviation (SD) and coefficient of variations (CV) of body measurements in yearling Dorper ewes

\begin{tabular}{lcc}
\hline Parameter & Mean \pm SD & CV $(\%)$ \\
\hline Live weight $(\mathrm{kg})$ & $48.0 \pm 5.75$ & 12.0 \\
Shoulder height $(\mathrm{cm})$ & $60.9 \pm 2.43$ & 3.99 \\
Chest dept $(\mathrm{cm})$ & $29.1 \pm 1.33$ & 4.57 \\
Shoulder width $(\mathrm{cm})$ & $21.5 \pm 1.22$ & 5.67 \\
Hindquarter width $(\mathrm{cm})$ & $18.3 \pm 1.02$ & 5.57 \\
Rump length $(\mathrm{cm})$ & $20.4 \pm 1.22$ & 5.98 \\
Pelvic width $(\mathrm{cm})$ & $6.6 \pm 0.45$ & 6.82 \\
Pelvic height $(\mathrm{cm})$ & $6.9 \pm 0.46$ & 6.67 \\
Pelvic area $\left(\mathrm{cm}{ }^{2}\right)$ & $35.55 \pm 4.89$ & 13.76 \\
Conformation score & $3.5 \pm 0.64$ & 18.28 \\
Selection score & $3.6 \pm 0.77$ & 0.21 \\
Chest projection score & $3.7 \pm 0.47$ & 12.70 \\
Rump slope score & $3.6 \pm 0.56$ & 15.56 \\
\hline
\end{tabular}


depicted in the small coefficients of variance. The PA recorded a small variance amongst yearling ewes. The same trend was observed for most other body measurements considered in this study.

Table 2 depicts the correlation coefficients between all variables considered in this study. In general, the correlations between all pelvic measurements were high $(r>0.77, P<0.0001)$, while the correlation between all other body measurements considered in this study was low $(r<0.26)$, although significant in most cases. The very high correlations recorded between PW and PA $\left(\mathrm{R}^{2}=0.94, P<0.001\right)$, as well as between $\mathrm{PH}$ and PA $\left(\mathrm{R}^{2}=0.84, P<0.001\right)$ can be explained by the fact that these two measurements ( $\mathrm{PH}$ and $\mathrm{PW})$ directly affect PA. The correlation between $\mathrm{PH}$ and $\mathrm{PW}$ was also high $\left(\mathrm{R}^{2}=0.77, P<0.001\right)$. According to Smith (2005) the growth in pelvic height and pelvic width differs between beef heifers of different frame sizes. According to Briedenhann (2010), pelvic width is more important in Bos taurus cattle while pelvic height is more important in Bos indicus cattle. It seems that in Dorper ewes, PW has a greater effect on PA than PH (i.e. 0.94 vs. 0.84, respectively). This is contrary to what was reported for beef heifers, in which differences in pelvic areas are usually attributed to differences in pelvic height (Anderson et al., 1994; Patterson et al., 1997).

Table 2 Phenotypic correlations between pelvic measurements and certain body parameters in Dorper ewes

\begin{tabular}{cccccccccccc}
\hline Parameter & BW & SH & CD & SW & HW & RL & PW & PH & PA & S & RS \\
\hline $\begin{array}{c}\text { Pelvic } \\
\text { width }\end{array}$ & $0.26^{* * *}$ & $0.12^{*}$ & $0.24^{* * *}$ & $0.11^{\mathrm{NS}}$ & $0.30^{* * *}$ & $0.04^{\mathrm{NS}}$ & - & $0.77^{* * *}$ & $0.94^{* * *}$ & $0.26^{* * *}$ & $0.20^{* * *}$ \\
$\begin{array}{c}\text { Pelvic } \\
\text { height }\end{array}$ & $0.24^{* * *}$ & $0.09^{\mathrm{NS}}$ & $0.24^{* * *}$ & $0.10^{\mathrm{NS}}$ & $0.24^{* * *}$ & $0.03^{\mathrm{NS}}$ & $0.77^{* * *}$ & - & $0.84^{* * *}$ & $0.25^{* * *}$ & $0.27^{* * *}$ \\
$\begin{array}{c}\text { Pelvic } \\
\text { area }\end{array}$ & $0.24^{* * *}$ & $0.10^{\mathrm{NS}}$ & $0.26^{* * *}$ & $0.12^{\mathrm{NS}}$ & $0.25^{* * *}$ & $0.05^{\mathrm{NS}}$ & $0.94^{* * *}$ & $0.84^{* * *}$ & - & $0.27^{* * *}$ & $0.26^{* * *}$ \\
& & & & & & & & & & &
\end{tabular}

Body weight (BW), Shoulder height (SH), Chest dept (CD), Shoulder width (SW), Hindquarter width (HW), Rump length (RL), Pelvic width (PW), Pelvic height (PH), Pelvic area with (PA), Conformation (CM), Selection (S), Chest projection (CP), Rump slope (RS)

Level of significance: $*=P<0.05, * *=P<0.01$, ${ }^{* * *}=P<0.001$, NS $=$ Non significant.

No similar studies for sheep could be found by the authors to compare results. Johnson et al. (1988) reported that rump slope in cattle has no influence on internal pelvic measurements or calving ease. However, Philipson (1976) and Dadati (1985) reported that in cattle, a sloping rump (subjectively scored) was associated with calving ease. The breed standards of the Dorper sheep prescribe a flatter rump as opposed to most other sheep, goat and cattle breeds. It remains to be seen whether phenotypic selection pressure for conformation and type (i.e. flat rump, hind quarter width, muscling, etc) has indirectly affected pelvic measurements and ease of lambing in Dorper ewes. In Table 3 the mean pelvic measurements, body

Table 3 Comparison of pelvic width, pelvic height, pelvic area, body weight, hind quarter according to selection type of yearling Dorper ewes

\begin{tabular}{|c|c|c|c|c|}
\hline Parameter & Selection type 2 & Selection type 3 & Selection type 4 & Selection type 5 \\
\hline No. of observations & $\mathrm{n}=22$ & $n=133$ & $\mathrm{n}=141$ & $\mathrm{n}=36$ \\
\hline Pelvic width (cm) & $6.44 \pm 0.4^{\mathrm{a}}$ & $6.39 \pm 0.7^{\mathrm{a}}$ & $6.70 \pm 0.4^{\mathrm{b}}$ & $6.73 \pm 0.4^{b}$ \\
\hline Pelvic height (cm) & $6.60 \pm 0.4^{\mathrm{a}}$ & $6.74 \pm 0.5^{\mathrm{a}, \mathrm{b}}$ & $6.96 \pm 0.4^{b, c}$ & $6.97 \pm 0.4^{\mathrm{c}}$ \\
\hline Pelvic area $\mathrm{cm}^{2}(\pi)$ & $33.51 \pm 3.8^{\mathrm{a}}$ & $33.99 \pm 5.3^{\mathrm{a}}$ & $36.72 \pm 4.3^{\mathrm{b}}$ & $39.97 \pm 4.3^{\mathrm{b}}$ \\
\hline Body weight (kg) & $44.1 \pm 6.2^{\mathrm{a}}$ & $46.6 \pm 5.8^{\mathrm{a}, \mathrm{b}}$ & $48.9 \pm 5.1^{\mathrm{b}}$ & $52.3 \pm 4.8^{\mathrm{c}}$ \\
\hline Hind quarter width $(\mathrm{cm})$ & $17.86 \pm 1.1^{\mathrm{a}}$ & $18.17 \pm 1.0^{\mathrm{a}}$ & $18.38 \pm 1.0^{\mathrm{a}}$ & $18.78 \pm 1.0^{\mathrm{b}}$ \\
\hline
\end{tabular}

${ }^{\mathrm{a}, \mathrm{b}, \mathrm{c}}$ Means with different superscripts within the same row differ significantly at $P<0.05$. 
weight and hind quarter width for different ewe types, as classified according to breeding standards, are shown.

From Table 3 it seems that there were no differences $(P>0.05)$ in pelvic measurements between the pelvic areas of types 2 and 3 or types 4 and 5 ewes, but types 4 and 5 ewes recorded higher pelvic height, width and area than types 2 and 3 ewes $(P<0.05)$. The exception was the similar pelvic heights of types 3 and 4 ewes. Although relatively small, type 5 ewes recorded a mean pelvic area of $6.46 \mathrm{~cm}^{2}$ greater than type 2 ewes $(P<0.05)$. It remains to be seen if such small difference would significantly affect ease of lambing in young Dorper ewes.

Selection type 5 ewes were larger $(P<0.05)$ with heavier and wider hindquarters than all other selection types. Furthermore, no significant correlations were found between linear body measurements and pelvic dimensions in ewes, indicating the need to measure the pelvic width and height directly and to calculate its area if selection for larger pelvic areas is intended. Hind quarter width, body conformation, rump slope, rump length and chest dept were the most important traits influencing the pelvic area of ewes. In a stepwise regression analysis, the combined contribution of all variables to the model discussed above was only 0.208 , indicating that there are other more important factors influencing pelvic area.

\section{Conclusions}

Results indicate that it was possible to obtain pelvic measurements in sheep using a pelvic meter. In general there were low correlations between linear body measurements and pelvic dimensions in yearling Dorper ewes. This means that to reduce dystocia, pelvises of sheep should be measured directly to calculate appropriate areas in order to eliminate ewes with lower pelvic areas, as this parameter is, according to literature, the most important factor influencing dystocia in sheep.

\section{Acknowledgements}

The authors would like to thank the Dorper Breeders' Society as well as the farmers who made their animals available for this study.

\section{References}

Anderson, L.H. \& Bullock, K.D., 1994. Pelvic measurements and calving difficulty. University of Kentucky Cooperative Extention Service, ASC-142, USA.

Briedenhann, J., 2010. Verbeter jou koeikudde. Meet pelvis vir kalwingsgemak. Chronicle. Desember 2010, pp. 12-18.

Dadati, E., Kennedy, B.W. \& Burnside, E.B., 1985. Relationships between conformation and reproduction in Holstein cows: Type and calving performance. J. Dairy Sci.68, 2639-2645.

Deutscher, G.H., 1975. Pelvic measurements for reducing calving difficulty. University of Nebraska, Extention Beef specialist. Product of Extension Beef Cattle Resource Committee.

Fourie, P.J., Neser, F.W., Olivier, J.J. \& Van der Westhuizen, C., 2002. Relationship between production performance, visual appraisal and body measurements of young Dorper rams. S Afr. J. Anim. Sci. 4, 256-262.

Hartwig, N., 2002. Sheep Health. Iowa State University of Science and Technology, U.S Department of Agriculture, USA.

Haughey, K.G. \& Gray, C.H., 1982. A radiographic technique for pelvimentry of unasaesthestised ewe and a comparison of three methods of estimating the area of the pelvic inlet. Aust. Vet. J. 58, 51-59.

Johnson, S.K., Deutscher, G.H. \& Parkhurst, A., 1988. Relationship of pelvic structure, body measurements, pelvic area and calving difficulty. J. Anim. Sci. 66, 1081-1088.

Kilgour, R.J. \& Haughey, K.G., 1993. Pelvic size in Merino ewes selected for lambrearing ability is greater than that of unselected Merino ewes. Anim. Reprod. Sci. 31, 237-242.

Maiwashe, A.N., 2000. The value of recording body measurements in beef cattle. M.Sc. (Agric). thesis, Bloemfontein, UOFS, South Africa.

Morrison, D.G., Williamson, W.D. \& Humes, P.E., 1986. Estimates of heritabilities and correlations of traits associated with pelvic area in beef cattle. J. Anim. Sci. 63, 432-437.

Patterson, J.P. \& Herring, W., 1997. Pelvic measurements and calving difficulty in beef cattle. G2017. University Extension. University of Missouri-Columbia, USA. pp. 1-3. 
Philipson, J., 1976. Studies on calving difficulty, still-birth and associated factors in Swedish cattle breeds. IV. Relationships between calving performance, precalving body measurements and size of pelvic opening of Friesian heifers. Acta. Agric. Scand. 26, 221-229.

SAS, 1989. Statistical Analysis System user's guide. (6th ed). SAS Institute Inc., Raleigh, North Carolina, USA.

Sieber, M., Freeman, A.E. \& Kelley, D.H., 1989. Effect of body measurements and weight on calf size and calving difficulty of Holsteins. J. Dairy Sci. 72, 2402-2410.

Smith, J.W., 2005. Correlation of pelvic shape and birth weight EPDs in reducing dystocia in beef cattle. MSc (Master of Science, Agricultural Operations Management) thesis, University of Tennessee, USA.

Walker, D., Ritchie, H. \& Hawkins, D., 1992. Pelvic measurements and calving difficulty in beef cattle. Michigan State University. Department of Animal Science: Charls Gibson Department of Large Animal Clinical Science, Michigan, USA. 